\title{
CONTRIBUIÇÕES PARA O TRABALHO COM VALORES EM EDUCAÇÃO AMBIENTAL
}

\section{Contributions to deal with values in Environmental Education}

\author{
Dalva Maria Bianchini Bonotto ${ }^{1}$
}

\begin{abstract}
Resumo: Neste artigo discute-se o trabalho com valores em Educação Ambiental, o que exige uma fundamentação e posicionamento adequados. Diante do impasse entre posições relativistas e universalistas para a educação em valores, aponta-se para a necessidade de explicitar nossa posição e ação em favor dos valores ambientalmente desejáveis, considerando que as questões envolvidas com o meio ambiente dizem respeito à vida e à sobrevivência de todos os seres do planeta. Estes valores podem ser identificados junto aos princípios presentes no "Tratado de educação global para sociedades sustentáveis e responsabilidade global", apresentado pela sociedade civil na ECO-92. Por fim, ressalta-se a necessidade de se desenvolverem estratégias educativas que envolvam as dimensões aqui denominadas de cognição, afetividade e ação, resultando em um trabalho abrangente, que amplie as possibilidades de o indivíduo apreender, de maneira mais efetiva, um dado valor, tendo, então, melhores condições de construí-lo em sua vida.

Palavras-chave: Educação ambiental. Conteúdo valorativo da Educação Ambiental. Educação em valores. Valores éticos e estéticos em Educação Ambiental.
\end{abstract}

\begin{abstract}
In this paper we discuss the value content of Environmental Education, because it requires an adequate theoretical basis and positioning. The relativist and universalistic positions are presented and it is pointed out that the environmental questions and their respective values mean much more than simple personal options. This is because the environmental questions concern life and the survival of all living beings on the planet. Thus, we must make our position and actions consistent with these values. They are identified in the principles reported in "Treatise for the global education for sustainable societies and global responsibility", which was elaborated by the civil society at ECO-92. It is also considered that values education is an issue focusing on the dimensions of cognition, feelings and action. All these three dimensions aim at achieving a broader result.
\end{abstract}

Keywords: Environmental Education. Value content of Environmental Education. Values education. Aesthetic and ethic values in Environmental Education.

${ }^{1}$ Professora doutora, Departamento de Educação do Instituto de Biociências da Unesp, campus de Rio Claro. <dalvambb@rc.unesp.br>

1 Avenida $24 \mathrm{~A}, \mathrm{n}^{\circ} 1515$

Rio Claro, SP

$13.506-900$ 


\section{Introdução}

Desde as primeiras reuniões internacionais organizadas em torno da Educação Ambiental (EA) na década de 1970, ao se discutirem as diretrizes gerais relativas a esse trabalho, é enfatizada a necessidade de não reduzi-lo à simples aquisição de conhecimentos. Vercher (1992), demonstrando tal ênfase, lista uma série de objetivos educacionais apresentados em documentos provenientes dessas reuniões, demonstrando o interesse por propostas educativas que atuem não apenas em termos de saber, mas também de querer e de fazer. Esses diferentes objetivos implicam uma visão de educação global, em que se considera e se propõe o trabalho com conteúdos de ensino de natureza variada.

Conforme Zabala (1998), embora o termo "conteúdo de ensino" seja geralmente utilizado para expressar conteúdos de caráter cognitivo relativos às disciplinares escolares, podemos considerar, como conteúdo de ensino, tudo o que se tem de aprender para alcançar vários objetivos, que não apenas os cognitivos. Nessa concepção, a tarefa educativa implica também outros tipos de conteúdos que dizem respeito às dimensões afetivas, valorativas e políticas da formação do cidadão, o que vem plenamente ao encontro das propostas anteriormente citadas sobre a EA.

Vale expor aqui a ressalva apontada por Zabala (1998, p. 40) com relação aos perigos de uma visão compartimentalizada do processo educativo: "Todo conteúdo, por mais específico que seja, sempre está associado e portanto será aprendido junto com conteúdos de outra natureza". A demarcação dessas dimensões, reforça o autor, decorre da necessidade de se garantir o trabalho explícito com todas elas, de modo que as atividades de aprendizagem, que são substancialmente diferentes segundo a natureza do conteúdo, sejam garantidas.

É com base nessa perspectiva que pretendo discutir a respeito do trabalho com o conteúdo valorativo da EA. Ele requer posicionamentos e estratégias de trabalho específicas, estas advindas da contribuição de autores que tratam da educação em valores. Dentre os diferentes posicionamentos e estratégias, é necessário ao educador que, identificando-os, faça suas escolhas.

No entanto, tenho verificado, tanto por meio de observações de práticas pedagógicas como de dados de literatura (BONOTTO, 2003, 1999; BENETTI, 1998; MANZOCHI, 1994), que os professores, de maneira geral, apresentam grandes dificuldades para trabalhar com esse conteúdo, frente a inúmeros questionamentos e desconhecimentos com os quais se deparam: é possível à escola educar em valores? Seria ético fazê-lo? Se afirmativo, com que valores trabalhar em EA? Como realizar esse trabalho?

Tomando por base a discussão dessas questões, busco apresentar algumas reflexões e posicionamentos que julgo adequados para o trabalho educativo com o tema.

\section{Valores universalmente desejáveis}

Em nossa vida cotidiana, constantemente estamos fazendo juízos de valor: julgamos as coisas, pessoas, situações, como boas ou ruins, atrativas ou não, segundo os valores que lhes atribuímos. Deste modo, os seres humanos, em sociedade e por meio de escolhas sucessivas, constroem formas de viver que se diferenciam em tempos e lugares diversos, originando os 
diferentes costumes e a criação de diferentes valores. $\mathrm{Na}$ medida em que certos valores se relacionam com regras e deveres, ou ao bem e a uma conduta boa, constituem os chamados valores morais.

Ao adentrarmos nesse campo de discussões, aproximamo-nos do campo da ética: uma reflexão que parte para a discussão, problematização e interpretação do significado dos valores morais (CHAUÍ, 2001).

A sociedade contemporânea, envolvida por uma gama crescente de mudanças e problemas que assolam o planeta em nível global, tem sido caracterizada por muitos como carente de reflexão ética, ocorrendo, no geral, uma falta de parâmetros para reflexão e ação diante dos desafios que se apresentam.

Para Grün (1994), isso é resultado da visão racionalista de mundo, fruto da Ciência Moderna, que promoveu a distinção e separação das dualidades sociedade e natureza, fato e valor, ciência e ética, com a desconsideração de um dos aspectos, o que levou à eliminação das reflexões éticas pela sociedade. Problemas atuais de dimensão planetária, como os ambientais, estão apontando para a urgência dessas reflexões, de modo a subsidiarem posicionamentos e ações mais éticas por parte da sociedade.

No entanto, diante do caráter histórico e cultural dos valores e da moral, advoga-se, por muitos, que não se devam ou possam estabelecer princípios dessa natureza para nossa sociedade, na defesa de uma postura livre e aberta a todo posicionamento, ou a toda cultura. Assim, segundo Araújo (2001), como resultado da crítica ao modelo autoritário universalista e em busca da liberdade, a sociedade contemporânea abriu-se para o relativismo dos valores, postulando que os valores seriam relativos e individuais, e que cada pessoa construiria seu próprio sistema de valores, independentemente do grupo social em que estivesse inserida.

Para esse autor, tal postura tem conduzido as relações sociais a um nível de individualismo tão exacerbado que pode ser considerado "uma vertente do autoritarismo ainda mais violenta, posto que idéias e práticas de exclusão são justificadas e naturalizadas a partir de interesses individuais ou de grupos econômicos e/ou ideologicamente dominantes" (ARAÚJO, 2001, p. 11).

Segundo Araújo (2001), o questionamento acerca do princípio que estabelece os valores universais - um princípio autoritário ao impor modelos de conduta, estabelecidos por culturas hegemônicas, a outras menos complexas ou menos articuladas do ponto de vista sociopolítico-econômico - não implica que devamos aceitar a relativização total de valores, considerando a moralidade sempre "local", ou que não existam valores melhores do que outros. Não podemos concordar com a hipótese de que "os valores assumidos por determinado grupo que defenda, por exemplo, a discriminação de pessoas "diferentes", devam ser respeitados pelo coletivo social democrático” (ARAÚJO, 2001, p. 13).

Diante disso, concordo com o autor ao considerar que a construção de relações sociais que de fato respeitem as diferenças passa pela incorporação de princípios e valores situados na confluência democrática entre direitos e liberdades individuais e os deveres para com a comunidade em que se vive.

Tomando como uma das bases possíveis desses princípios aqueles pertencentes à Declaração Universal dos Direitos Humanos, elaborada pela Organização das Nações Unidas em 1948 (ARAÚJO, 2001) apresenta, por meio dessas mesmas bases, os chamados valores universalmente desejáveis: 
Bonotto, D. M. B.

A premissa de que existam valores universalmente desejáveis permite a sistematização de alguns valores que valham para a maioria das culturas (ou pelo menos para as culturas mais complexas), sem perder, ao mesmo tempo, a referência de que existem limites para essa universalização, enfatizando que os valores próprios de cada cultura devem ser respeitados e assumidos como tais. Esses valores, portanto, podem ser tomados por nossa cultura como desejáveis, mas isso não nos dará o direito de os impor às demais. (ARAÚJO, 2001, p. 13)

Assim, princípios e valores como a justiça, a igualdade, etc, apesar de não deverem ser impostos a toda e qualquer cultura do planeta, para nós, ocidentais, devem ser desejáveis, devido ao caráter de universalização que assumem no contexto social, servindo, não somente como um guia de referência para a análise dos conflitos de valores vivenciados em nosso diaa-dia, como também para a elaboração de programas educacionais que objetivem uma educação em valores ou educação moral.

Nesses programas não se realizaria um trabalho impositivo, de doutrinação, mas com base em situações diversas criadas pela escola (MENIN, 2002), dar-se-ia a apresentação, reflexão, crítica, vivência desses guias de referência, possibilitando a construção de valores por parte de todos os envolvidos com tais exercícios.

\section{Valores ambientalmente desejáveis}

Tomando por base a reflexão anterior, reforço meu posicionamento junto àqueles que, embora não aceitem atrelar o trabalho com valores em EA a uma postura de inculcação de valores (o que significaria colaborar com a formação de indivíduos heterônomos, dependentes), têm claro que, com respeito a esse tema, é preciso ir além da proposta de uma educação vista como uma questão exclusiva de se favorecerem "escolhas pessoais".

Como as questões envolvidas com o meio ambiente dizem respeito à vida e à sobrevivência de todos os seres do planeta, tais questões - e os valores a elas associados abrangem muito mais que opções pessoais. Nesse caso, deve ser explícita nossa posição em favor desses valores, que denomino valores ambientalmente desejáveis, constituindo-se mais uma base possível de trabalho relativo aos valores universalmente desejáveis.

Com base nesses pressupostos, podemos identificar os valores ambientalmente desejáveis junto aos princípios presentes no "Tratado de educação global para sociedades sustentáveis e responsabilidade global", elaborado pela sociedade civil e apresentado na ECO-92. Esse documento, que aponta para aspectos imprescindíveis na construção de uma sociedade sustentável, afirma "valores e ações que contribuem para a transformação humana e social e para a preservação ecológica” (VIEZER e OVALLES, 1994, p. 29). Tendo sido construído diretamente pela sociedade civil, tal documento pode ser considerado representativo de seus valores, anseios e entendimentos.

Os princípios apresentados nesse documento se relacionam basicamente a duas esferas: "uma, da relação dos seres humanos entre si; a outra, da relação dos seres humanos com os outros seres com os quais compartilham o planeta" (MANZOCHI, 1994, p. 309); e apon- 
tam para elementos, práticas e idéias a serem assumidos como valores e que estão envolvidos com a:

. Valorização da vida: não somente a dos seres humanos, mas a de todos os seres vivos. Essa posição acarreta, como conseqüência, o respeito e valorização da biodiversidade e a necessidade de a sociedade rever sua posição em relação aos demais habitantes com os quais compartilha o planeta.

- Valorização da diversidade cultural: ao se valorizar a comunidade dos seres vivos de maneira ampla, incluem-se as sociedades humanas em seus aspectos não somente natural, mas também cultural. Isso se opõe a atitudes de desconsideração de outras culturas que não a nossa.

. Valorização de diferentes formas de conhecimento: ao valorizarmos diferentes culturas, também nos abrimos para as diferentes formas de conhecimento ou saberes, por elas estabelecidos. Isso se contrapõe à hegemonia do conhecimento científico, então considerado superior e suficiente para apreender - e dominar - o mundo.

- Valorização de uma sociedade sustentável: busca-se um modelo de sociedade baseado na sustentabilidade eqüitativa e qualidade de vida para todos, no lugar da superprodução e superconsumo para alguns e conseqüente pobreza para a maioria, o que implica o reajuste dos modelos atuais da economia da tecnologia.

- Valorização de uma vida participativa: para a construção de uma sociedade justa, equilibrada, nos aspectos social e ambiental, despontam valores como responsabilidade, solidariedade, cooperação e diálogo, possibilitando a todos a participação, em um processo democrático e autônomo, nessa construção.

O conjunto de valores presentes nesses princípios representa nosso grande desafio como educadores interessados em EA, no sentido de sua promoção junto à sociedade.

Considero, entretanto, ser necessário ainda destacar, para esse conjunto, um item importante: trata-se da valorização estética da natureza.

Desde a $1^{\circ}$ Conferência Intergovernamental sobre EA, ocorrida em 1977, os princípios então estabelecidos para a EA apontavam a necessidade de se considerar o ambiente em sua totalidade, incluindo-se os aspectos estéticos.

A apreciação estética sendo gratuita, desinteressada, levaria a uma "percepção totalizante" do objeto (ARANHA e MARTINS, 1991); ela representaria outra forma de apreensão da realidade, que "não visa o conhecimento lógico, medido em termos de verdade; não visa a ação imediata e não pode ser julgada em termos de utilidade para determinado fim" (p. 381). Assim considerada, a apreciação estética nos permitiria ampliar nossa apreensão da natureza. Abrir-se para esta outra forma de conhecimento, portanto, com a conseqüente valorização da dimensão estética da natureza, poderia contribuir, significativamente, para a construção de nova forma de relação ser humano-natureza.

Forquin (1982) reforça essas idéias, ao apresentar a sensibilização ao meio ambiente enquanto um dos objetivos da Educação Artística, apontando-a como uma tarefa tanto de ordem política quanto pedagógica. Esse autor afirma que o papel das atividades estéticas na aprendizagem do meio ambiente consiste em dar ênfase aos aspectos mais diretamente sensoriais e sensíveis, ensinando-se aos alunos por meio de exercícios de variações dos estímulos, pois, em nossa percepção comum, costumamos perceber mal, muito depressa e superficialmente. Essa seria uma educação das aparências, base de um "domínio efetivo do mundo 
sensível, [...] meio de habitar o mundo de modo mais intenso e significativo" (FORQUIN, 1982, p. 28).

Segundo o autor, essa tarefa não é simples, pois nosso olhar cotidiano dirige-se às utilidades, e não às aparências. A sensibilização ao meio ambiente pressupõe, para Forquin (1982, p. 29), um desvio do caminho habitual: "é preciso perceber o mundo como uma paisagem, como uma soma de estímulos, não como uma série de utensílios".

Concluindo, é na articulação do valor estético da natureza aos éticos, anteriormente identificados, que estruturo o conjunto básico de valores ambientalmente desejáveis a serem trabalhados em EA, com o intuito de subsidiar a construção de uma sociedade mais justa e ambientalmente mais responsável, detentora de um padrão de relação sociedade-natureza mais adequado.

\section{Educação em valores}

Continuando as reflexões em torno do trabalho educativo com o conteúdo valorativo da EA, há outro aspecto fundamental a ser considerado: trata-se do modo como se educa em valores.

Esse trabalho comumente é encarado como uma transmissão legada pelas gerações mais velhas às mais novas, e isso porque, na maioria dos modelos educacionais, parte-se "do pressuposto epistemológico de que o conhecimento é algo exógeno em relação ao sujeito, que o internalizaria a partir de suas experiências sensoriais com o mundo externo" (ARAÚJO, 2001, p. 14). Para esse autor, no caso da educação moral não é diferente. Geralmente, não se considera o papel ativo do sujeito que interpreta e confere sentido aos conteúdos oferecidos pelo mundo externo, nem se leva em conta o papel de seus sentimentos e emoções, em seu funcionamento psíquico e em sua interpretação da realidade.

Contrariamente a esse modelo e concordando com Araújo (2001), a opção teórica que fundamenta este trabalho apóia-se em uma concepção construtivista. Os valores são construídos na interação entre um sujeito imbuído de razão e emoções e um mundo constituído de pessoas, objetos e relações. Dessa maneira, são construídos "a partir do diálogo e da qualidade de trocas que são estabelecidas com as pessoas, grupos e instituições em que se vive" (ARAÚJO, 2001, p. 15).

Assim, cada qual constrói seu sistema de valores, em que alguns valores "posicionamse" como mais centrais ou mais periféricos na identidade do sujeito. Esses valores transformam-se em valores morais na medida em que se vinculam com conteúdos de natureza moral, ou seja, na medida em que o alvo das projeções afetivas positivas assume natureza ética (ARAÚJO, 2001). Esse modelo construtivista-interacionista para a educação em valores é originário dos estudos de Piaget. Conforme esclarece-nos Araújo (2001) ao falar de valores, com base na perspectiva piagetiana, referimo-nos inicialmente a uma troca afetiva que o sujeito realiza com o exterior. Os valores surgem da projeção dos sentimentos positivos sobre objetos, pessoas e/ ou relações, e, mais tarde, com as trocas interpessoais e a intelectualização dos sentimentos, são cognitivamente organizados com base nos julgamentos de valor que realizamos.

Apoiado nessas idéias, Kohlberg desenvolveu a teoria de estágios de desenvolvimento do juízo moral, em que a psicogênese da moralidade é vista nos mesmos esquemas da 
psicogênese do pensamento lógico. Estendendo suas pesquisas até a idade adulta e a sujeitos de diferentes nacionalidades e culturas, buscou encontrar princípios de desenvolvimento de caráter universal, independente da língua e da cultura. Postulou a existência de uma seqüência hierárquica composta por seis estágios de desenvolvimento do juízo moral, baseados no princípio de justiça, que vai se tornando cada vez mais integrado e universalizado à medida que o sujeito avança na construção desses estágios (ARAÚJO, 1999).

Muitas críticas a esse modelo teórico têm apontado para diversos aspectos dos quais ele não dá conta. Uma delas discute o fato de que o mesmo associa o juízo moral basicamente ao aspecto cognitivo, não contemplando uma outra dimensão fundamental do desenvolvimento humano e importante na construção dos valores, que é a afetividade.

Concordo com a crítica que se faz às propostas que enfatizam o aspecto cognitivo, em detrimento da dimensão relativa à afetividade ${ }^{2}$. A dicotomia cognição/ afetividade, enraizada no modelo racionalista da sociedade ocidental, levou, progressivamente, à desconsideração da dimensão afetiva de nossas vidas, acarretando, em conseqüência, sua dissociação e até desconsideração no processo educativo como um todo.

Sastre e Moreno (2002) consideram a dissociação razão-emoção uma das crenças mais fortemente arraigadas em nossa cultura. As autoras apontam que o estudo conjunto da afetividade e da inteligência, já iniciado nos últimos anos nas áreas da neuropsicologia e psicologia, vem, gradativamente, desmontando essa crença, ao identificar a profunda interação entre cognição e afetividade.

Diante da relação tão estreita entre esses aspectos, essas autoras advertem que não se pode desenvolver um sem levar em conta o outro. No entanto, no currículo escolar, a crença antiga leva a um desequilíbrio dessa relação, "que conduz a uma sociedade muito bem preparada para progredir no campo da tecnologia - inclusive a militar - mas deixa a tecnologia em mãos [...] de analfabetos emocionais" (SASTRE e MORENO, 2002, p. 30).

Sastre e Moreno (2002) consideram, assim, indispensável à escola realizar um trabalho mais abrangente, de inclusão da dimensão afetiva. Segundo elas, seria um trabalho de conhecimento dos sentimentos e das emoções, um trabalho cognitivo, implicando uma tomada de consciência dos próprios estados emocionais, das causas suscetíveis de provocar cada um deles e de suas conseqüências. Essa proposta metodológica se apóia em uma abordagem construtivista (mais concretamente na epistemologia genética), ressaltando que, se a maioria desses trabalhos voltava-se para o desenvolvimento cognitivo, "os ensinos deles extraídos são de grande utilidade no momento de abordar o desenvolvimento emocional, cujo funcionamento, como assinalamos anteriormente, não se pode considerar dissociado daquele" (SASTRE e MORENO, 2002, p. 47).

\footnotetext{
${ }^{2}$ A afetividade aqui se refere "ao conjunto de fenômenos psíquicos que se manifestam sob a forma de emoções, sentimentos e paixões, acompanhados sempre da impressão de dor ou prazer, de satisfação ou insatisfação, de agrado ou desagrado, de alegria ou tristeza" (FERREIRA, s/d, p. 44).
} 
Vejo que, nessa proposição, reside ainda um problema que encontro com freqüência entre aqueles que estão à procura do resgate da dimensão afetiva: até que ponto não permanecemos restritos ainda a uma visão racionalista, que tenta apenas "pensar a emoção", procurando inclusive garantir o seu controle?

Analisando a teoria piagetiana de desenvolvimento do juízo moral, La Taille (1992) considera que, nela, a afetividade, embora reconhecida como ingrediente importante na construção do juízo moral, se dobra à razão. Esta prevalece para avaliar racionalmente o ideal de honestidade, de justiça, etc, portanto, uma solução incompleta: "Piaget nos fornece a condição necessária ao desenvolvimento da moral autônoma, mas não a condição suficiente" (LA TAILLE, 1992, p. 72). Para esse autor, saber não é necessariamente querer; embora ressalte que o estudo do juízo não deixe de ser essencial (a não ser que se afirme a total independência entre pensar e agir), ele destaca a necessidade de que esse estudo seja completado por outros, que se detenham mais nos aspectos afetivos do problema.

Sinto que a falta dessa complementação teórica se traduz na carência do trabalho com a dimensão afetiva entre aqueles que lidam com a educação em valores. Mergulhados no paradigma racionalista dominante, geralmente falta-nos visão para conceber um trabalho mais amplo. A maioria concorda que é preciso considerar a afetividade; fala-se em "lidar" com as emoções, "considerá-las", "trabalhar" com elas; mas não se explicita como fazê-lo. Ou então as propostas restringem-se ao identificar para (tentar) controlar. Não negando o valor desse trabalho, penso que é preciso ampliar a proposta.

Com relação a esta questão, acredito que alguns autores, que lidam com a educação estética, oferecem elementos importantes para o trabalho com a dimensão afetiva da educação em valores, implicando uma melhor complementaridade cognição/afetividade nas atividades pedagógicas. Assim, na presente proposta de trabalho com valores em EA, além de apontar a dimensão estética da natureza como aspecto essencial a ser valorizado e trabalhado em EA, também destaco a experiência estética como possibilidade rica para o trabalho genérico com valores.

Em verdade, a idéia da possibilidade da interação cognição/afetividade ou razão/ emoção não é recente, embora tenha sido sufocada pela visão racionalista de mundo (GRÜN, 1996) e seu pensamento simplificador (MORIN, 1990). Schiller (1995), já no século XVIII, reconhecia na antiga civilização grega uma fase em que esse equilíbrio teria existido, quando "os sentidos e o espírito não tinham ainda domínios rigorosamente separados", ocorrendo, posteriormente, seu rompimento, tornando o homem segmentado: "eternamente acorrentado a um fragmento do todo, o homem pode formar-se enquanto fragmento" (SCHILLER, 1995, p. 40-41). Em sua proposta de educação estética, esse autor considera que a natureza humana só poderá ser conduzida à plenitude de seu desenvolvimento na medida em que conjugar suas forças sensíveis (sensações) e racionais.

Marcuse (1986), analisando a dimensão estética, entende que, em seu significado e função originais, ela estaria associada com prazer, sensualidade, beleza, verdade, arte e liberdade, em que "o termo visa a uma esfera que preserva a verdade dos sentidos, e reconcilia, na realidade da liberdade, as faculdades 'inferiores' e 'superiores' do homem, sensualidade e intelecto, prazer e razão" (p. 156).

O autor tece comentários a respeito das "Cartas sobre a educação estética do homem", de Schiller (1995), que foram escritas, em grande parte, sob o impacto da "Crítica do 
juízo" de Kant. Para Marcuse (1986), em ambos os trabalhos encontrar-se-ia a idéia de se reconstruir a civilização com base na força libertadora da função estética, em que a razão é sensual e a sensualidade racional:

Como foi a própria civilização que 'aplicou ao homem moderno esta ferida', só um novo modo de civilização poderá curá-la. A ferida é causada pela relação antagônica entre as duas dimensões da existência humana [...] A cultura é um produto da combinação e interação destes dois impulsos. Mas na civilização estabelecida, a sua relação tem sido antagônica; em vez de reconciliar ambos os impulsos, tornando a sensualidade racional e a razão sensual, a civilização submeteu a sensualidade à razão de modo tal que a primeira, se acaso logra reafirmar-se, o faz através de formas destrutivas e "selvagens", enquanto a tirania da razão empobrece e barbariza a sensualidade. (MARCUSE, 1986, p. 166)

Também Restrepo (1998), caminhando em direção semelhante, explicita claramente a necessidade que vê de articular-se a educação em valores "ao campo da estética sugestiva que nos permita [...] inscrever-nos na trama de uma educação do gosto e da sensibilidade" (RESTREPO, 1998, p. 10). Esse autor vai além, propondo uma síntese sugestiva entre o campo da estética e o da ética, ao considerar esta última um tema relacionado com certas formas de sensibilidade, ou seja, mais às percepções que às proposições, pois,

Independentemente das cadeias argumentais que conseguimos formular, as decisões vitais - matar ou não matar, impor ou co-gerir são tomadas dependendo da maneira como percebemos o outro ou os outros no entorno cotidiano. O que acaba por decidir nossa atitude ética é a afetação sensível, a disposição corporal a conviver nessa engrenagem de implícitos e não ditos que caracterizam o espaço humano. A paixão é a grande artesã do conhecimento. (RESTREPO, 1998, p. 58)

Ressalto, assim, que a educação em valores deve corresponder a uma proposta em que a cognição e a afetividade se articulem com peso equivalente e possam, juntas, subsidiar a ação.

Essa ação torna-se, a um só tempo, resultante e promotora da construção desses valores, pois, afinal, "não se ensina cooperação como um valor sem a prática da cooperação, [...] não se ensina tolerância sem a prática do diálogo. Na perspectiva piagetiana há uma clara opção pelos métodos ativos de educação moral” (MENIN, 2002, p. 97).

Reconheço por fim, concordando com Araújo (1999, p. 67), que há necessidade de se "estruturar uma teoria moral que contemple a complexidade do ser humano, seu momento histórico e cultural, seus interesses pessoais e suas relações com o mundo". Para esse autor, 
estamos falando, pois, de um ser que é biológico, afetivo, social e cognitivo ao mesmo tempo, sem que um desses aspectos possa ser considerado mais importante que o outro, já que qualquer perturbação ou alteração no funcionamento de algum desses subsistemas afeta o funcionamento da totalidade do sistema. (ARAÚJO, 1999, p. 68)

Com base nessas diversas críticas e vários estudos que têm apontado para os diferentes aspectos envolvidos com a construção de valores pelos indivíduos, muitos autores (MARQUES, 1998; PUIG, 1998a; IOZZI, 1989, CADUTO, 1984/85) têm destacado os benefícios de se trabalhar com diferentes estratégias de ensino, provindas, inicialmente, de abordagens teóricas diferenciadas, a fim de realizar um trabalho educativo mais amplo.

Dessa forma, Puig (1998a) reúne as propostas advindas da teoria do desenvolvimento do juízo moral a outras que tentam abarcar os aspectos que aquelas não contemplam, procurando integrar esses vários referenciais em um quadro mais amplo de educação. Assumindo a educação moral como construção da personalidade moral, Puig (1998b) reconhece e entrelaça aspectos que os vários referenciais apresentam, enquadrando-os de forma que estabeleçam uma complementação e permitam um trabalho mais abrangente. Embora essas propostas estejam separadas por objetivos específicos diversificados, todas elas devem se integrar aos objetivos gerais de construir: consciências morais autônomas, a percepção e o controle dos sentimentos e emoções, e a competência dialógica.

Também Marques (1998), ao apresentar os vários modelos de educação em valores, de diferentes autores, que partem de focos distintos sobre reflexão, emoção e conduta moral, sugere que os programas de educação moral devem procurar integrar os três, considerando que o desenvolvimento moral é produto de todos esses componentes.

Fundamentada nessas reflexões, apresento uma proposta de educação em valores que objetiva lidar de forma equilibrada com três dimensões, que deverão estar sempre interligadas:

- Cognição: reflexão sobre as idéias, concepções, sentimentos e valores relativos a um foco de interesse (um dado assunto ou objeto, valores a ele associados ou, mesmo, um valor em si), permitindo a elaboração de compreensões, análises e juízos de valor a seu respeito;

- Afetividade: trabalho de sensibilização e envolvimento, identificação e expressão dos sentimentos; de apreciação estética com relação ao valor apresentado.

- Ação: vivência de situações reais de envolvimento com o valor apresentado/desejado, buscando a complexidade das experiências, a serem tanto apreciadas como refletidas. A construção de um valor, em última instância, se revelará no plano da ação, como hábitos ou atitudes coerentes com o valor construído.

Vejo, nessas três dimensões, a possibilidade de incorporação das propostas anteriores, com relação às estratégias já apresentadas para o trabalho com valores (PUIG, 1998a), acrescidas da proposta de apreciação estética (DUAR'TE-JÚNIOR, 1988; RESTREPO, 1998).

Assim, por exemplo, o diálogo, tido como um valor a ser apresentado aos alunos, seria trabalhado tanto em situações concretas de diálogo a respeito de uma dada situação controversa a ser debatida, em momentos de reflexão mais genérica sobre seu papel, como também apreciado esteticamente por meio de uma obra artística ou da própria criação estético-expressiva dos alunos. 
No trabalho com essas três dimensões, reconheço a possibilidade de se incorporarem diferentes estratégias educativas, buscando proporcionar não apenas oportunidades de se identificar e refletir sobre um dado valor, mas, também, apreciá-lo esteticamente, assim como, na medida do possível, trazê-lo para a vida real, por meio de ações que sejam com ele coerentes.

Considero que a articulação desses três tipos de experiências pode ampliar o trabalho com valores, favorecendo as possibilidades de o indivíduo apreender de maneira mais efetiva um dado valor, o que resulta, conseqüentemente, em melhores condições para sua escolha e construção.

\section{Referências}

ARANHA, M. L. A. A.; MARTINS, M. H. P. Filosofando: introdução à Filosofia. São Paulo: Moderna, 1991.

ARAÚJO, U. F. Os direitos humanos na sala de aula: a ética como tema transversal. São Paulo: Moderna, 2001.

. Conto de escola: a vergonha como um regulador moral. Campinas: Editora da Unicamp/Moderna, 1999.

BENETTI, B. A temática ambiental e a perspectiva do professor de Ciências. 1998. 169 p. Dissertação (Mestrado em Educação Brasileira) - Faculdade de Filosofia e Ciências da Unesp, Marília, 1998.

BONOTTO, D. M. B. O trabalho com valores em Educação Ambiental: investigando uma proposta de formação contínua de professores. 2003. 231f. Tese (Doutorado em Educação) - Centro de Educação e Ciências Humanas, Universidade Federal de São Carlos, São Carlos, 2003.

A temática ambiental e a escola pública de Ensino Médio: conhecendo e apreciando a natureza. 1999. 278f. Dissertação (Mestrado em Conservação e Manejo de Recursos) - Centro de Estudos Ambientais, Universidade Estadual Paulista, Rio Claro, 1999.

CADUTO, M. J. A teacher training model and educational guidelines for environmental values education. The Journal of Environmental Education, v. 16, n. 2, p. 30-34, 1984/85.

CHAUÍ, M. Convite à Filosofia. 12. ed. São Paulo: Ática, 2001.

DUARTE-JÚNIOR, J. F. Fundamentos estéticos da educação. Campinas: Papirus, 1988.

FERREIRA, A. B. H. Novo dicionário da língua portuguesa. Rio de Janeiro: Nova Fronteira, s/d. $15^{\circ}$ re-impressão.

FORQUIN, J-C. A educação artística - para quê? In: PORCHER, L. Educação artística luxo ou necessidade? São Paulo: Summus Editorial, 1982. p. 25-48. 
Bonotto, D. M. B.

GRÜN, M. Uma discussão sobre valores éticos em Educação Ambiental. Educação \& Sociedade, v. 19, n. 2, p. 171-195, 1994.

Ética e Educação Ambiental: a conexão necessária. Campinas: Papirus, 1996.

IOZZI, L. A. What research says to educator. Part two: environmental education and the affective domain. Journal of Environmental Education, v. 20, n. 4, p. 6-13, 1989.

LA TAILLE, I. Desenvolvimento do juízo moral e afetividade na teoria de Jean Piaget. In: LA TAILLE, Y.; OLIVEIRA, M. K; DANTAS, H. Piaget, Vigotsky, Wallon: teorias psicogenéticas em discussão. São Paulo: Summus Editorial, 1992. p. 47-73.

MANZOCHI, L. H. Participação do ensino de Ecologia em uma Educação

Ambiental voltada para a formação da cidadania: a situação das escolas de $2^{\circ}$ grau no município de Campinas. 1994. 544f. Dissertação (Mestrado em Ecologia) - Instituto de Biociências, Universidade Estadual de Campinas, Campinas, 1994.

MARCUSE, H. Eros e civilização: uma interpretação filosófica do pensamento de Freud. Rio de Janeiro: Guanabara Koogan, 1986.

MARQUES, R. Ensinar valores: teorias e modelos. Porto: Porto Ed, 1998.

MENIN, M. S. S. A. Valores na escola. Educação e Pesquisa, v. 28, n. 1, p. 91-100, 2002.

MORIN, E. Introducción al pensamiento complejo. Barcelona: Gedisa, 1990.

PUIG, J. M. Ética e valores: métodos para um ensino transversal. São Paulo: Casa do Psicólogo, 1998a.

A construção da personalidade moral. São Paulo: Ática, 1998b.

RESTREPO, L. C. O direito à ternura. Rio de Janeiro: Vozes, 1998.

SASTRE, V.; MORENO, M. Resolución de conflictos y aprendizage emocional: una perspectiva de género. Barcelona: Gedisa, 2002.

SCHILLER, F. A educação estética do homem. São Paulo: Iluminuras, 1995.

VERCHER, M. R. El aprendizage de valores en educación ambiental. Madrid: Centro de Publicaciones de Secretaria General Técnica/Ministerio de Obras Públicas y Transportes, 1992.

VIEZER, M.; OVALLES, O. (Orgs.). Manual Latino-americano de Educação ambiental. São Paulo: Editora Gaia, 1994.

ZABALA, A. A prática educativa: como ensinar. Porto Alegre: Artmed, 1998.

Artigo recebido em fevereiro de 2007 e aprovado em junho de 2007. 